\title{
Self-awareness rehabilitation after Traumatic Brain Injury: A pilot study to compare two group therapies
}

\author{
Jessica Rigon $^{\mathrm{a}, *}$, Roberto Burro ${ }^{\mathrm{b}}$, Cecilia Guariglia $^{\mathrm{c}}$, Manuela Maini $^{\mathrm{d}}$, Dario Marin $^{\mathrm{e}}$, Paola Ciurli ${ }^{\mathrm{c}}$, \\ Umberto Bivona $^{\mathrm{c}}$ and Rita Formisano ${ }^{\mathrm{c}}$ \\ ${ }^{a}$ IRCCS Fondazione Ospedale San Camillo, Venezia Lido, Italy \\ ${ }^{\mathrm{b}}$ Università degli Studi di Verona, Dipartimento di Scienze Umane, Verona, Italy \\ ${ }^{\mathrm{c}}$ IRCCS Santa Lucia, Roma, Italy \\ ${ }^{\mathrm{d}}$ CRA Nucleo Speciale Gravissime Disabilità Virginia Grandi, Bologna, Italy \\ ${ }^{\mathrm{e}}$ IRCCS E. Medea, Pordenone, Italy
}

\begin{abstract}
.
Background and Purpose: Deficits of self-awareness (SA) are very common after severe acquired brain injury (sABI), especially in traumatic brain injury (TBI), playing an important role in the efficacy of the rehabilitation process. This pilot study provides information regarding two structured group therapies for disorders of SA.

Methods: Nine patients with severe TBI were consecutively recruited and randomly assigned to one SA group therapy programme, according either to the model proposed by Ben-Yishay \& Lakin (1989) (B\&L Group), or by Sohlberg \& Mateer (1989) (S\&M Group). Neuropsychological tests and self-awareness questionnaires were administered before and after a 10 weeks group therapy.

Results: Results showed that both SA and neuropsychological functioning significantly improved in both groups.

Conclusion: It is important to investigate and treat self-awareness, also to improve the outcome of neuropsychological disorders. The two group therapies proposed seem to be specific for impulsivity and emotional dyscontrol and for cognitive disorders.
\end{abstract}

Keywords: Self-awareness disorders, traumatic brain injury, group therapy, rehabilitation, GLMMs

\section{Introduction}

Traumatic Brain Injury (TBI) is defined as an alteration in brain function, or other evidence of brain pathology, caused by an external force (Menon et al., 2010). Self-awareness (SA) deficits are very frequent after severe Traumatic Brain Injury (TBI) (Ben-Yishay et al., 1985; Prigatano et al., 1986; Freeland, 1996; Sherer, 1998a; Sherer et al., 2003;

\footnotetext{
*Corresponding author: Dr. Jessica Rigon, IRCCS Fondazione Ospedale San Camillo, Via Alberoni 70, 30126, Venezia Lido, Italy. Tel.: +39 0412207516; Fax: +39 0412207262; E-mail: jessica.rigon@ospedalesancamillo.net.
}

Bivona et al., 2008; Ciurli et al., 2010) and can compromise patients' outcomes (Schmidt et al., 2011). SA has been defined as "the ability to perceive the self in terms of relatively goals while keeping a sense of subjectivity" (Prigatano \& Schachter, 1991), as well as "the quality of man that allows not only the selfawareness, but also to understand itself within the social environment" (Stuss \& Benson, 1986). In the field of TBI, SA has also been defined as the "the ability to recognize deficits, understand their functional implications and establish realistic goals" (Crosson et al., 1989; Fleming et al., 1996), as well as "the ability to anticipate the difficulties, recognize errors or 
monitor their performance in his conduct" (Toglia \& Kirk, 2000).

Crosson and colleagues (1989) proposed a hierarchical model consisting of three levels of SA: intellectual, emerging and anticipatory SA. According to the authors, a patient can be first intellectually self-aware of his own deficits to experience emergent and, consequently, anticipatory SA. Other authors (Toglia \& Kirk, 2000) proposed an interactional model between the different types of SA, which provides a dynamic relationship between knowledge, beliefs, task demands and context of a situation. According to this model, metacognitive knowledge (or declarative knowledge) about one's abilities incorporates elements of intellectual awareness, while online monitoring of performance during tasks relates to emergent awareness and anticipatory awareness (Toglia \& Kirk, 2000). More recently, Ownsworth \& Clare (2006) proposed a more complex model of SA, taking into account the role played by biopsychosocial factors underlying SA.

A variety of measures and methods for assessing SA have been proposed in the literature (Markova \& Berrios, 2006), which involve clinician, relative and patient ratings. Different methods have been used to assess SA like structured or semi-structured interviews, self-report questionnaires, spontaneous verbal reports of difficulties and also methods that compare patients' judgment with their neuropsychological performance (Fisher et al., 2004; Fleming et al., 1996; Sbordone et al., 1998; Sohlberg et al., 1998). The most widely used method is to compare patients' rating with those of a clinician or family member (Fleming et al., 1996).

SA deficits can especially compromise patients' activity of daily life functioning (Wood, 2008; Ownsworth \& Clare, 2006). Indeed, patients with poor SA may show low compliance and poor motivation for any rehabilitation treatment, and subsequent difficulties in social and work integration are known. Consequently, improving SA is an important goal for any rehabilitation process (Flashman \& McAllister, 2002).

In the literature, several rehabilitation interventions for SA after TBI have been reported. A review identified a range of awareness treatments that include holistic milieu-oriented neuropsychological programmes, psychotherapy, compensatory and facilitator approaches, structured experiences, direct feedback, videotaped feedback, confrontational techniques, cognitive therapy, group therapy, game formats and behavioural intervention (Fleming \&
Ownsworth, 2006). Feedback interventions are the common factors to all approaches on SA disorders, listed above. However, even if feedback interventions can improve SA, the evidence based on the efficacy of a particular kind of feedback is still poor, and further researches are recommended (Schmidt et al., 2011). Moreover, evidences of group therapy efficacy in SA deficits of individuals with TBI are scant.

Group therapy has been indicated for rehabilitation of functions such as attention and memory (Spencer, 1993), pragmatic communication (Mazzucchi \& Avanzi, 1998), emotion and behaviour (Prigatano, 1986) and to promote social and family integration (Prigatano et al., 2005), and its efficacy in treating cognitive, emotional and behavioural consequences of TBI has been shown (Carberry \& Burd, 1983; Prigatano, 1986). Group therapy allows a comparison and sharing of similar experiences among patients. This experience facilitates awareness of both patients' difficulties and abilities, and can increase their self-esteem (Sohlberg \& Mateer, 1989). Furthermore, structured group therapy programmes help patients with acquired brain injury to develop coping strategies (Lundqvist et al., 2010).

In the present paper we referred to two different and specific approaches for SA rehabilitation, based on group therapy: Ben-Yishay \& Lakin (1989) and Sohlberg \& Mateer (1989) models. Both approaches are based on a cognitive-behavioural (CB) rehabilitation, providing structured and timing established activities, which allowed a comparison between these models.

However, the diagnosis of the level of SA was the main focus of investigation, before starting group therapy.

This study aimed at verifying the efficacy of two group therapies based on the two mentioned programmes for SA disorders, in a homogenous sample of adults patients with severe TBI. SA levels were measured before and after both treatments, by using three widely used questionnaires: the Patient Competency Rating Scale (PCRS, Prigatano et al., 1986), the Awareness Questionnaire (AQ, Sherer et al., 1998a, 1998b, 1998c, 2003), and the Self-Awareness of Deficit Interview (SADI, Fleming et al., 1996; Simmond \& Fleming, 2003). Evaluation was performed by a blind neuropsychologist with regards to the type of group therapy.

The secondary aim of this study was to examine whether the SA improvements induced by the two different treatments would have positive impacts on the other impaired neuropsychological functions. 
Indeed, an increased awareness of deficits should improve the ability to anticipate and prevent difficulties as well as the capability to monitor behavioural deficits allowing to correct them. TBI patients present with a variety of clinical problems, including physical impairments, motor and cognitive deficits. Actually this makes very difficult to match individuals in different groups and, in absence of large samples, results less reliable. For this reason, and because it would be not ethical to exclude patients from treatment, we decided to avoid the recruitment of a control group which would not be treated with any SA group therapy.

\section{Methodology}

\subsection{Participants}

Nine TBI inpatients at the Post-Coma Unit of Santa Lucia Foundation in Rome were consecutively recruited. The inclusion criteria were the following: (1) age >15 years; (2) diagnosis of severe TBI: Glasgow Coma Scale (GCS) (Teasdale \& Jennett, 1974) score $\leq 8$; (3) post-traumatic amnesia (PTA) resolution (Artiola et al., 1980); (4) capacity to undergo formal psycho-metric evaluation despite cognitive and sensory-motor deficits; (5) presence of SA disorders; (6) availability of informed consent; (7) availability of a caregiver. Exclusion criteria were a history of drug or alcohol addiction, the presence of psychiatric diseases or aphasia, and repeated TBI.

All patients were treated with standard rehabilitation programmes, such as physiotherapy, cognitive and occupational therapy. The study was approved by the Santa Lucia Foundation ethical committee.

Thirty patients were enrolled among the population of persons with severe TBI, consecutively admitted for rehabilitation to the Santa Lucia Foundation. Thirty patients met the inclusion criteria, but 10 were excluded because of lack of collaboration or motivation to be enrolled in the group therapy, 3 because of aphasia, 3 because of persistent post-traumatic amnesia, 2 for history of drug addiction and 2 for alcohol abuse. The enrolled patients were randomly included in the 2 group therapies.

One patient dropped out after a few sessions of group therapy, due to caregiver's difficulty to accompany the patient to the group therapy sessions. Thus, the final sample consisted of 9 participants ( 7 males and 2 females), with a mean age of 24.1 years (range:
18-38) and a mean educational level of 10.7 years (range: 8-13).

\subsection{Group therapy programmes}

In the group who has undergone the Ben-Yishay and Lakin (1989) treatment (B\&L group), nine topics, four cognitive-behavioural exercises and individual role play were planned. Role playing was the main activity in which each patient, in turn, was the protagonist of the session. The protagonist sat in front of the therapist; she or he was involved in an activity, such as the job he or she was doing before having the accident, or such as a daily activity. The other patients were instructed to observe carefully the protagonist's performance and to make notes on their sheets. Before receiving the feedback from the others, the protagonist was invited to assess his or her performance. Finally, also the psychologist leader provided his o her feedback; executive leadership style was used.

In the other group (Sohlberg \& Mateer, 1989) (S\&M Group), instead, we proposed activities related to TBI through lessons and discussions. In particular, lessons concerning cognitive and behavioural disorders resulting after TBI were carried out; instead, discussions on patients' experiences or with other experiences proposed through head injury films were compared among participants. According to this group therapy programme, the activities were performed in specific units named as follow: members' presentation, head injury film, problem lists, sequence race, party activities and emotional experiences about brain injury. The buddy system, therapist coach and democratic leadership were the main techniques used in this group therapy programme.

\subsection{Clinical data}

The following clinical data related to severity of TBI were collected: GCS scores at the acute phase; Time to Follow Commands (TFC) for the duration of the disorders of consciousness (Dikmen et al., 1986; Dikmen et al., 1994; Katz \& Alexander, 1994); post-traumatic amnesia (PTA) duration (Artiola et al., 1980; Novack et al., 1992; Fryer \& Haffey, 1987); and Glasgow Outcome Scale (GOS) (Jennett \& Bond, 1975), Disability Rating Scale (DRS) (Rappaport, 2005; Rappaport et al., 1982, 1989; Hall et al., 1985), and Levels of Cognitive Functioning (LCF) (Hagen et al., 1972; Levin et al., 1979; Mc Millan et al., 1996) scores, at time of recruitment, for the disability evaluation. 
Table 1

Demographic, Clinical and Functional data of participants recruited in both group therapies.

A Mann-Whitney U-Test was performed in order to test differences between samples

\begin{tabular}{lcccccc}
\hline & B\&L (median) & S\&M (median) & B\&L (IQR) & S\&M (IQR) & $\mathrm{z}$ & $p$-value \\
\hline Age (years) & 21 & 25 & 8 & 6.5 & -0.244 & 0.806 \\
Education & 10 & 10.5 & 5 & 5 & 0 & 1 \\
GCS & 3 & 3 & 0 & 2.5 & -0.122 & 0.902 \\
GOS & 3 & 3 & 0 & 0 & 0 & 1 \\
DRS & 14 & 10.5 & 4 & 6.5 & 1.347 & 0.177 \\
TFC (days) & 45 & 30 & 40 & 8 & 1.347 & 0.177 \\
PTA (days) & 150 & 102.5 & 150 & 145 & 0.612 & 0.540 \\
LCF & 6 & 6.5 & 0 & 1 & -1.224 & 0.220 \\
\hline
\end{tabular}

Note: GCS = Glasgow Coma Scale; GOS = Glasgow Outcome Scale; DRS = Disability Rating Scale; TFC = Time to Follow Commands; PTA = Post-Traumatic Amnesia; LCF = Levels of Cognitive Functioning; IQR = InterQuartile Range.

Demographic, clinical and functional data of all participants (Median and InterQuartile Range values) are reported in Table 1. A Mann-Whitney U-Test was performed in order to test differences between samples. No significant difference was detected.

\subsection{Neuropsychological assessments and procedures}

\subsubsection{Neuropsychological tests}

Spatial and temporal orientation (Bianchi et al., 2014; Bianchi et al., 2013), logical reasoning (Branchini et al., 2015), attention, memory, language, and executive functioning were assessed by using a neuropsychological battery which included the following tests: Space and Temporal Orientation (Spinnler \& Tognoni, 1987), Raven Test (Raven, 1954; Basso et al., 1987), Wisconsin Card Sorting Test (WCST) (Heaton et al., 1993, 2000), Verbal and Semantic Fluency (Novelli et al., 1986), Tower of London (Krikorian et al., 1994), Attention Test Battery (Zimmerman \& Fimm, 1992), Digit Backward and Forward Span Test (Orsini, 2003), Corsi Span Test (Orsini et al., 1987), Episodic Memory Test (Novelli et al., 1986) and 15 Words Rey Test (Rey, 1987; Carlesimo et al., 1996). All the tests were administered in the Italian validated version.

\subsubsection{Self-awareness assessment}

SA levels was assessed by widely used selfawareness questionnaires, the Patient Competency Rating Scale (PCRS, Prigatano, et al., 1986), the Awareness Questionnaire (AQ, Sherer et al., 1998a, 1998b, 1998c, 2003a) and the Self-Awareness of Deficit Interview (SADI, Fleming et al., 1996; Simmond \& Fleming, 2003).
PCRS and AQ assess metacognitive SA and were completed by both the patient and a relative, with the assistance of a neuropsychologist. Both questionnaires are based on a 5-point Likert scale and provide two parallel versions, one for the patient and the other for a family member (or significant other). PCRS is a 30 -items self-report questionnaire, and provide assessment of four domains (daily living, cognitive, interpersonal and emotional). It assesses patients' current abilities by a patient's self-report ranging from 1 ("Can't do") to 5 ("Can do with ease"). An overall assessment of SA deficit was obtained by using the method of discrepancy score (PCRSDS) between total patient and total relative score; a cut-off point of \pm 5 points was taken into account to discriminate whether or not a SA deficit was present (Prigatano et al., 1998).

AQ is a 17-items self-report questionnaire which assesses present skills in relation to patients preinjury ability, by a patient's self-report ranging from 1 ("much worse") to 5 ("much better"). The AQ discrepancy scores (AQ-DS) can range from -68 to 68: a score of 51 indicates that the patient's functioning is the same as his/her pre-injury level.

PCRS and AQ higher positive discrepancy scores (patient-relative) are associated with severe SA deficits, while negative scores are rare and might show a patient's overestimation of his impairment (Cicerone, 1991; Prigatano \& Altman, 1990), possibly due to a high level of emotional distress (Fleming et al., 1998; Godfrey et al., 1993) or to the development of self-limiting belief systems in which TBI patients overrate the effects of their injury in everyday life (Moore \& Stambrook, 1995).

The SADI is a semi-structured interview that was administered only to patients and consists of three sections in which clinician can rate patient's answers 
by scoring from 0 (no disorder of self-awareness) to 3 (severe disorder of self-awareness). The three sections can be summed to give a maximum possible score of 9 , with higher scores indicating more severe impairment of self-awareness. The score is based on a judgment of the clinician performing the interview.

Consequently, data obtained by all above questionnaires integrated clinician, caregiver and patient perspectives, providing a comprehensive assessment of SA. Indeed, clinician rating can be an objective measure regarding the patient's current condition, but only close relatives can provide additional information about pre-morbid (such as personality and/or abilities in daily living) functioning.

After neuropsychological and SA evaluation, ten individuals, homogeneous for TBI functional severity and SA disorders, were selected. Five patients were randomly included into the B\&L Group, and the others into the S\&M Group. According to the former model, we proposed to the B\&L Group some structured activities and used the role-play technique. Instead, according to the latter model, we proposed to the S\&M Group some group discussions based on problems and difficulties emerged after the TBI.

Both groups have undergone their specific rehabilitation treatment for 10 weeks, with a frequency of a meeting per week. In each group and session, three psychologists were present: one as a conductor and coordinator (coach) of the activities, another as co-therapist and the third performing videotaping. A brief description of the main activities which have been carried out has been reported above in the methodology session.

\subsection{Statistical analysis}

All analysis were performed by means of Renvironment for statistical computing ( $\mathrm{R}$ Core Team, 2015).

The distributions of the SA and neuropsychological data have been analysed employing Box-Cox transformations (Box \& Cox, 1964). According to lamba-values data were distributed logarithmically or normally. Thus, for both groups (B\&L and S\&M) we performed general linear mixed models (GLMMs), using lme4 package (Bates et al., 2015) of the R-software on dependent variables based on a Gaussian or Log-distribution, with an Identity-link function. In particular, in the analysis of awareness data the GLMMs were adopted considering as follow: discrepancy score (DS) as dependent variable, groups, pre-post questionnaires and subscales as fixed-effects, identification (ID) subjects as random effect, independently for AQ, PCRS and SADI.

Instead, in the analysis of neuropsychological data, the GLMMs were performed for each cognitive test adopted, using: score as dependent variable, groups, pre-post as fixed effect, ID subjects and levels as random effects.

In order to control the family-wise error (FWE), also known as alpha inflation or cumulative Type I error, and taking into account the small number of patients in each group, we adopted the correction method developed in detail by Benjamini \& Hochberg (1995), later reconsidered by Benjamini \& Yekutieli (2001) and before briefly mentioned by Simes (1986), that evaluates the false discovery rate (FDR), the expected proportion of false discoveries amongst the rejected hypotheses. The FDR is a less stringent condition than in the case where the familywise error rate (FWER) is controlled (Holm, 1979; Hochberg, 1988; Hommel, 1988), so this method is more powerful than others. Since the cost of a false negative (missing a potentially important discovery) is fairly-high, we decided to use a FDR threshold equal to 0.15 , in order to not miss anything important (McDonald, 2014).

\section{Results}

Nine patients ( 7 males and 2 females), with a mean age of 24.1 years (ranging from 18 to 38 ) and an interval from TBI recruitment of 320 days (ranging from 103 to 664) were enrolled in the study. Table 1 shows the demographic, clinical, and functional data of the two groups (Mann Whitney U-Test).

Each patient has been blindly assessed with all the measures of SA (PCRS, AQ and SADI), at the beginning and at the end of the group therapy (after 10 weeks); each caregiver, instead, completed the relatives forms of both PCRS and AQ. Each subscale, relating to specific domains, included respectively in each questionnaire, were also analyzed separately.

At the baseline the PCRS-DS ranged from -16 to 34 (B\&L Group, from -16 to 34; S\&M Group, from -10 to 12$)$ and the AQ DS ranged from -13 to 28 (B\&L Group, from 13 to 28; S\&M Group, from -13 to 10). In particular, as for the PCRS, in which a PCRS DS cut off of \pm 5 points establishes the severity of SA deficit (Prigatano et al., 1998), we included 5 patients with poor SA (PCRS DS $\geq 5$ ), 1 patient with adequate SA (PCRS DS $<5$ ) and 3 patients with heightened SA (PCRS DS $<-5$ ). As in an our previous 
Table 2

Awareness questionnaires. Analysis of Deviance Table (Type II Wald chi-square tests)

\begin{tabular}{|c|c|c|c|c|c|c|}
\hline Tests & Fixed effects & Chisq & Df & $p$-value & FDR & Comparison of means \\
\hline \multirow[t]{7}{*}{ PCRS } & Groups (B\&L vs S\&M) & 0.634 & 1 & 0.425 & 0.802 & \\
\hline & Pre-Post & 2.240 & 1 & 0.134 & 0.402 & \\
\hline & Sub-scale & 19.511 & 3 & $0.0002 *$ & $0.001^{* *}$ & Cogn. $>$ Inter. $>$ Emot. $>$ Daily. \\
\hline & Groups $\times$ Pre-Post & 2.254 & 1 & 0.110 & 0.385 & \\
\hline & Groups $\times$ Sub-scale & 12.677 & 3 & $\mathrm{0.005}^{*}$ & $0.021^{* *}$ & 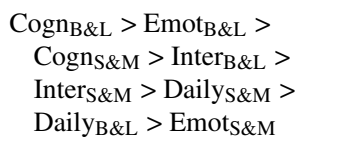 \\
\hline & Pre-Post $\times$ Sub-scale & 3.768 & 3 & 0.287 & 0.753 & \\
\hline & Groups $\times$ Pre-Post $\times$ Sub-scale & 2.419 & 3 & 0.490 & 0.802 & \\
\hline \multirow[t]{7}{*}{ AQ } & Groups (B\&L vs S\&M) & 0.041 & 1 & 0.837 & 0.925 & \\
\hline & Pre-Post & 0.018 & 1 & 0.893 & 0.937 & \\
\hline & Sub-scale & 39.017 & 2 & $0.0001 *$ & $0.001^{* *}$ & Cogn. $>$ Behav-aff. > Sens-mot. \\
\hline & Groups $\times$ Pre-Post & 9.125 & 1 & $\mathrm{O.002}^{*}$ & $0.010^{* *}$ & $\begin{array}{l}\text { Post }_{S \& M}>\text { Pre }_{B \& L}> \\
\text { Pre }_{S \& M}>\text { Post }_{B \& L}\end{array}$ \\
\hline & Groups $\times$ Sub-scale & 1.823 & 2 & 0.401 & 0.802 & \\
\hline & Pre-Post $\times$ Sub-scale & 0.002 & 2 & 0.998 & 0.998 & \\
\hline & Groups $\times$ Pre-Post $\times$ Sub-scale & 0.735 & 2 & 0.692 & 0.889 & \\
\hline \multirow[t]{7}{*}{ SADI } & Groups (B\&L vs S\&M) & 0.740 & 1 & 0.389 & 0.802 & \\
\hline & Pre-Post & 29.868 & 1 & 0.0001* & $\mathbf{0 . 0 0 1}^{* *}$ & Pre $>$ Post \\
\hline & Sub-scale & 1.411 & 2 & 0.497 & 0.802 & \\
\hline & Groups $\times$ Pre-Post & 0.101 & 1 & 0.749 & 0.889 & \\
\hline & Groups $\times$ Sub-scale & 0.875 & 2 & 0.645 & 0.889 & \\
\hline & Pre-Post $\times$ Sub-scale & 0.542 & 2 & 0.762 & 0.889 & \\
\hline & Groups $\times$ Pre-Post $\times$ Sub-scale & 0.101 & 1 & 0.749 & 0.889 & \\
\hline
\end{tabular}

Main results: general linear mixed models (GLMMs) with score as dependent variable; groups, pre-post and sub-scale as fixed effects; ID subjects as random effect. The rightmost column shows the order of means (from the largest to smallest) for the significant results. Note: *significant $(p$-value $<0.05)$; ${ }^{* *}$ significant FDR $(\mathrm{FDR}<0.15)$.

study (Ciurli et al., 2010), given the small sample size we chosed to consider both patients with good SA and with heightened SA as with good SA. The two experimental groups were composed, as follows: 2 patients with good SA and 2 with poor SA in S\&M Group, and 2 patients with good SA and 3 with poor SA into B\&L Group. Finally, using SADI questionnaire, the total score ranged from 6 to 8 in the B\&L Group, and from 3 to 9 in the S\&M Group.

After 10 weeks group therapy, the same assessment was performed by a blind evaluator. The PCRS-DS varied from -28 to 30 (B\&L Group, from 1 to 30; S\&M Group, from -28 to 9) and AQ DS ranged from -6 to 27 (B\&L Group, from 3 to 17; S\&M Group, from -6 to 27). In particular, as for the PCRS-DS, after therapy the groups were respectively formed by 1 patient with good SA and 4 with poor SA in B\&L Group, and by 3 patients with good SA and 1 with poor SA into S\&M Group. Finally, total score in SADI ranged from 0 to 8 (B\&L Group, from 2 to 7 ; S\&M Group, from 0 to 8 ). Table 2 reports principal outcomes of GLMMs for the same questionnaires.

As for the data reported in Table 2, five significant results were found. Two interactions [Group $\times$ SubScale in PCRS $(p$-value $=0.005 ; \quad \operatorname{FDR}=0.021)$ and Group $\times$ Pre-Post in AQ ( $p$-value $=0.002$; $\mathrm{FDR}=0.010)$ questionnaires] determined the main difference between groups. Secondarily main effects of some Sub-scales in PCRS were found $(p$-value $=0.0002 ; \quad \mathrm{FDR}=0.001), \quad$ in $\mathrm{AQ}$ $(p$-value $=0.0001 ; \mathrm{FDR}=0.001)$, as well as a main effect of Pre-Post in SADI ( $p$-value $=0.0001$; $\mathrm{FDR}=0.001$ ) questionnaire. The most relevant difference between groups related to the emotional subscale (Fig. 1, graphical representation on the left) and the inversion of score between groups in Pre-Post questionnaires (Fig. 1, graphical representation on the right).

As for the neuropsychological measures, statistically significant differences after SA therapy were found. Particularly, as shown in Table 3, two main differences between groups emerged: a) in Alert Attention test $(p=0.021 ; \mathrm{FDR}=0.129)$ and $\mathrm{b})$ in Verbal and Semantic Fluency ( $p$-value $=0.020$; FDR $=0.129$ ). Indeed, as reported in Fig. 2 (Fig. 2, on the left), Group S\&M showed smaller reaction times in TAP phasic alertness, indicating a best performance after therapy; in the same figure (Fig. 2, on the right) Group S\&M showed higher scores in Verbal and Semantic Fluency, indicat- 


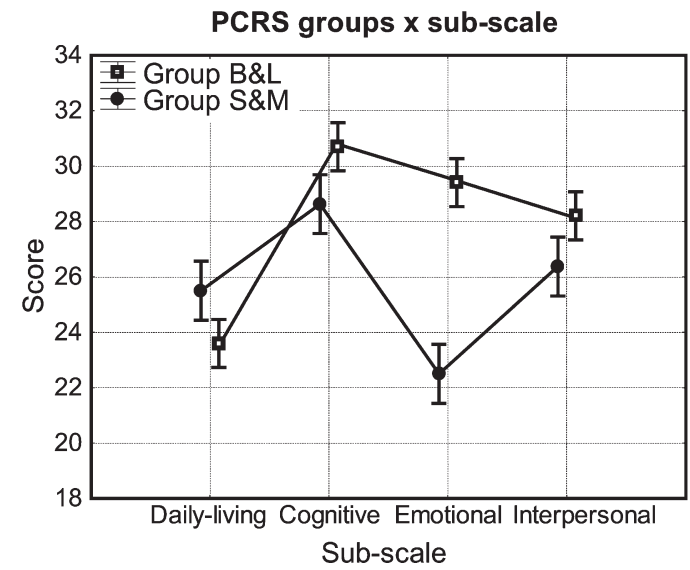

$A Q$ Groups x Pre-post questionnaires

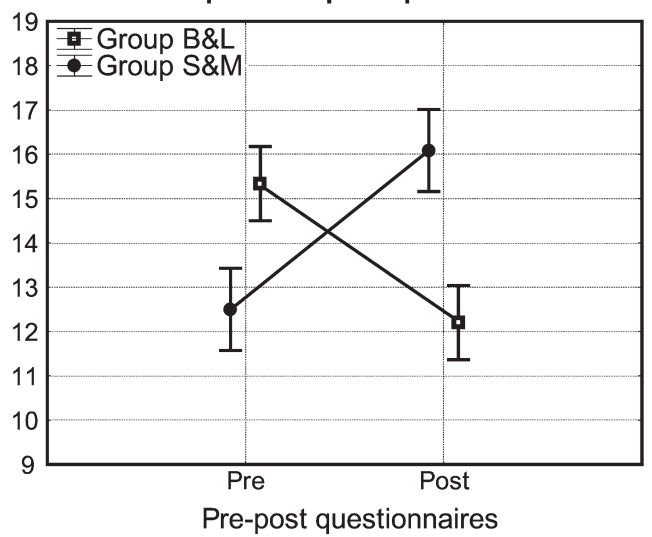

Fig. 1. Awareness questionnaires. Graphical representation of the most important Table 2 significant results. The vertical bars represent $+/-$ standard error. On the left: significant interaction effect of "Groups" and "sub-scale" in PCRS. The most relevant difference between B\&L Group and S\&M Group is for "emotional" subscale. On the right: significant interaction effect of Groups and pre-post questionnaires in AQ. In the pre-condition the score is higher for B\&L Group; in post-condition is vice-versa.

ing a best performance on access to lexicon. Other secondary significant effects have occurred, precisely three significant interaction effects between Groups and Pre-Post in Corsi Span $(p$-value $=0.027$; FDR $=0.129$ ), in Episodic Memory ( $p$-value $=0.020$; $\mathrm{FDR}=0.129)$ and in TAP alertness with sound ( $p$-value $=0.010 ; \quad$ FDR $=0.120)$. Lastly, a main effect of Pre-Post variable in naming test Bada $(p$-value $=0.024 ; \mathrm{FDR}=0.129)$, in Corsi Span $(p$ value $=0.004 ;$ FDR $=0.064)$, in Digit Span Forward $(p$-value $=0.025 ; \mathrm{FDR}=0.129)$, in Episodic Memory ( $p$-value $=0.0001 ; \mathrm{FDR}=0.002)$ and in Raven Progressive Matrices ( $p$-value $=0.0001 ; \mathrm{FDR}=0.002$ ) were found.

A power-analysis has been performed by calculating the sample size required for the comparison of two independent means between B\&L group and S\&M group for awareness questionnaires and neuropsychological data. The sample size takes into account:

- Type I error $-\alpha$-level $=0.05$ : the probability of making a Type I error (two-sided);

- Type II error - $\beta$-level $=0.20$ (the power of the test is 0.80 or $80 \%$ ): the probability of making a Type II error ( $\beta$-level)

- Means Difference (MD), standard deviations (SD-B\&L, SD-S\&M) and ratio of sample sizes (Ratio B\&L/S\&M): the calculated mean difference, standard deviations and ratio of sample sizes between $\mathrm{B} \& \mathrm{~L}$ group and $\mathrm{S} \& \mathrm{M}$ group for all awareness questionnaires and neuropsychological data.
The results are summarized in Table 4. For most significant data, the number of subjects is adequate for our research.

Figure 1 reports the most important graphical details of the significant results for awareness questionnaires, precisely only the cases in which a difference between the groups was obtained.

Figure 2 reports the most important graphical details of the significant results for neuropsychological data, precisely only the cases in which a main difference between the groups was obtained.

\section{Discussion}

It is well known that impaired SA in patients with TBI negatively impacts on both the outcome of rehabilitation and everyday life functioning as well as independent living, even at very long distance from TBI. In literature many rehabilitation interventions for SA disorders have been proposed; however, to our knowledge, studies on specific group interventions on SA disorders are scant. This is mainly due to the fact that individuals with TBI present with an high level of clinical heterogeneity, making very difficult to select homogeneous samples for TBI severity and levels of SA. Furthermore, persons with TBI and SA, because of their difficulty to collaborate, due to the lack of motivation that is part of the SA disorder, show poor compliance to rehabilitation treatment and very easily leave the studies. All together, that makes very difficult and time-consuming the selection of 

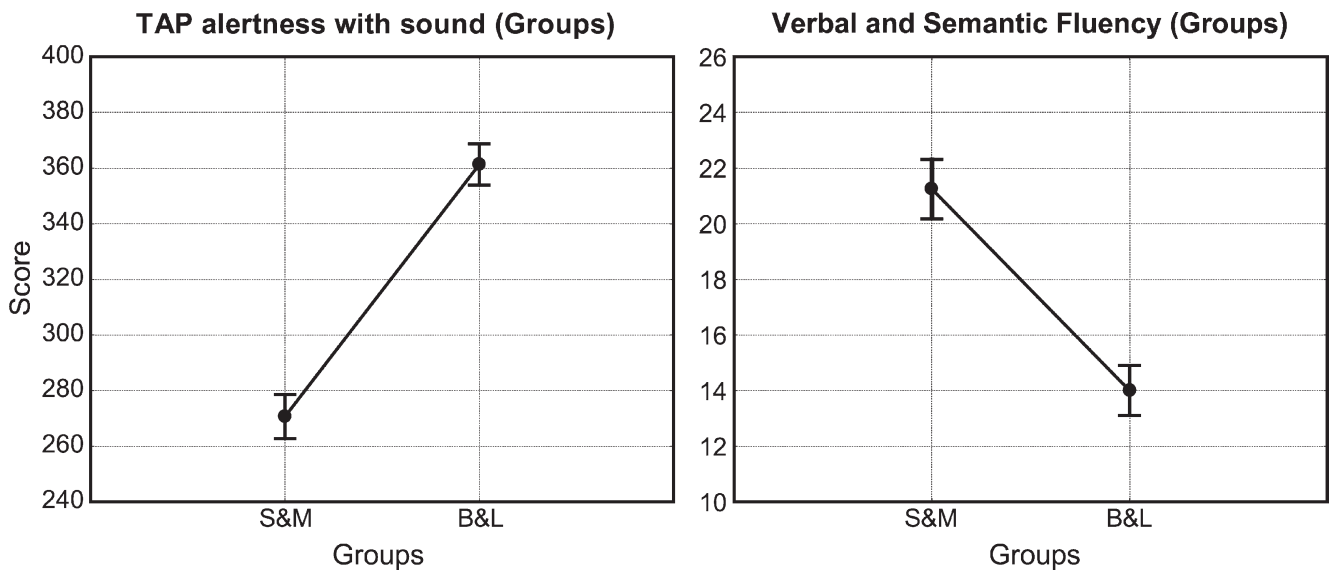

Fig. 2. Neuropsychological data. Graphical representation of the most important Table 3 significant results. The vertical bars represent $+/-$ standard error. On the left: significant main effect of "Groups" in TAP alertness with sound. The score is higher for B\&L Group. On the right: significant main effect of "Groups" in Verbal and Semantic Fluency. The score is higher for S\&M Group.

individuals with TBI for group studies and limits the research to single case reports or to of a small group populations, generally submitted to a single group treatment and analysed as a series of single case. In the present study, fully aware of the limits that studies including reduced samples of individuals have, we decided to compare two groups of TBI homogenous for SA severity and degree of disability, receiving two types of SA group therapy with the aim not only to test their efficacy, but also to unveil whether the two treatments, focusing on different aspects for SA, differently affect the associated neuropsychological deficits. Indeed, an effective treatment of awareness deficit would result not only in the improvement of SA, but should affect all the daily life activities, by improving patients' capability to prevent and correct errors, to monitor and self-regulate behaviour, to adopt and use compensatory strategies.

The present study, comparing two group therapy programmes, specific for SA disorders, were originally designed to enhance the collaboration and the compliance to the rehabilitation program in individuals with severe TBI and to increase SA levels and the motivation to treatment, in order to improve their final outcome.

Despite the small sample sizes, even more our encouraging results suggest the importance of a group intervention to improve self-awareness and neuropsychological outcomes. Indeed, the main finding of the present study consists of the SA improvement, that has been observed after SA group therapies. Compared to baseline, SA improved in both group therapies, although with some peculiarities in each group. First of all, considering the effects involv- ing differences between groups, significant results emerged in each group, even if with different questionnaires. In B\&L Group smaller discrepancy scores between patient and caregiver ratings have been evidenced after therapy, as resulted by AQ. Similarly, PCRS allowed to show smaller DS after treatment in the S\&M Group (Table 2, column of comparison of means). Since these results were found using two different questionnaires, AQ and PCRS, in both groups, the use of both questionnaires could be suggested. The results are probably due to the specificity of the treatments, that have been proposed in the two group therapies. In fact, B\&L therapy is mostly based on role-play technique, in which patient is involved in activities (such as job or daily living), already carried out by the patients before TBI, and AQ overtly requires a comparison between patient's current abilities and his/her pre-injury abilities. Instead, in S\&M Group, the group activities consisted of discussions about post-TBI cognitive and behavioural disorders, which are measured by PCRS in the current condition. However, both questionnaires are comparable in providing a measure of the SA disorder, confirming the efficacy of both approaches of treatment. Particularly the most relevant difference between B\&L Group and S\&M Group regarded the emotional aspects (Fig. 1, on the left) and the inversion of score in pre-post questionnaires (Fig. 1, on the right). The first result is due to the type of therapy, in fact, activities based on emotions specifically in S\&M Group were conducted. The second one, instead, is another important aspect that emerges from the patient/relative discrepancies. In the B\&L Group, as emerged in AQ, the DS were smaller after 
Table 3

Neuropsychological data. Analysis of Deviance Table (Type II Wald chi-square tests)

\begin{tabular}{|c|c|c|c|c|c|c|}
\hline Tests & Fixed effects & Chisq & Df & $p$-value & FDR & Comparison of means \\
\hline \multirow[t]{3}{*}{15 Word Rey Immediate } & Groups & 0.815 & 1 & 0.366 & 0.995 & \\
\hline & Pre-post & 0.604 & 1 & 0.437 & 0.995 & \\
\hline & Groups $\times$ Pre-post & 0.001 & 1 & 0.976 & 0.995 & \\
\hline \multirow{3}{*}{ Bada (namimg test) } & Groups & 2.333 & 1 & 0.126 & 0.549 & \\
\hline & Pre-post & 4.250 & 1 & $0.024 *$ & $0.129^{* *}$ & Pre $>$ Post \\
\hline & Groups $\times$ Pre-post & 2.074 & 1 & 0.149 & 0.596 & \\
\hline \multirow[t]{3}{*}{ Corsi span } & Groups & 0.029 & 1 & 0.864 & 0.995 & \\
\hline & Pre-post & 8.028 & 1 & $0.004 *$ & $0.064^{* *}$ & Post $>$ Pre \\
\hline & Groups $\times$ Pre-post & 4.535 & 1 & $0.027^{*}$ & $0.129^{* *}$ & $\begin{array}{c}\text { Post }_{S \& M}>\text { Post }_{B \& L}> \\
\text { Pre }_{B \& L}>\text { Pre }_{S \& M}\end{array}$ \\
\hline \multirow{3}{*}{ Digit span forward } & Groups & 0.286 & 1 & 0.592 & 0.995 & \\
\hline & Pre-post & 2.998 & 1 & $0.025^{*}$ & $0.129 * *$ & Pre $>$ Post \\
\hline & Groups $\times$ Pre-post & 0.246 & 1 & 0.619 & 0.995 & \\
\hline \multirow[t]{3}{*}{ Episodic memory } & Groups & 0.461 & 1 & 0.496 & 0.995 & \\
\hline & Pre-post & 12.343 & 1 & 0.0001* & $\mathbf{0 . 0 0 2}^{* *}$ & Pre $>$ Post \\
\hline & Groups $\times$ Pre-post & 4.989 & 1 & $\mathrm{0.0203}^{*}$ & $\mathbf{0 . 1 2 9}^{* *}$ & $\begin{array}{c}\text { Post }_{B \& L}>\text { Post }_{S \& M}> \\
\text { Pre }_{B \& L}>\text { Pre }_{S \& M}\end{array}$ \\
\hline \multirow{3}{*}{ H Barrage } & Groups & 0.745 & 1 & 0.388 & 0.995 & \\
\hline & Pre-post & 0.305 & 1 & 0.580 & 0.995 & \\
\hline & Groups $\times$ Pre-post & 0.068 & 1 & 0.793 & 0.995 & \\
\hline \multirow[t]{3}{*}{ Orientation } & Groups & 0.591 & 1 & 0.441 & 0.995 & \\
\hline & Pre-post & 0.189 & 1 & 0.663 & 0.995 & \\
\hline & Groups $\times$ Pre-post & 0.601 & 1 & 0.437 & 0.995 & \\
\hline \multirow[t]{3}{*}{ Raven Prograssive Matrices } & Groups & 0.006 & 1 & 0.934 & 0.995 & \\
\hline & Pre-post & 22.056 & 1 & 0.0001* & $\mathbf{0 . 0 0 2}^{* *}$ & Pre $>$ Post \\
\hline & Groups $\times$ Pre-post & 0.0382 & 1 & 0.845 & 0.995 & \\
\hline \multirow[t]{3}{*}{ TAP- alertness (with sound) } & Groups & 4.765 & 1 & $0.021 *$ & $0.129 * *$ & $\mathrm{~B} \& \mathrm{~L}>\mathrm{S} \& \mathrm{M}$ \\
\hline & Pre-post & 0.782 & 1 & 0.376 & 0.995 & \\
\hline & Groups $\times$ Pre-post & 6.369 & 1 & $0.010^{*}$ & $0.120^{* *}$ & $\begin{array}{c}\text { Pre }_{B \& L}>\text { Post }_{B \& L}> \\
\text { Post }_{S \& M}>\text { Pre }_{S \& M}\end{array}$ \\
\hline \multirow[t]{3}{*}{ TAP- divided attention } & Groups & 0.062 & 1 & 0.802 & 0.995 & \\
\hline & Pre-post & 0.006 & 1 & 0.936 & 0.995 & \\
\hline & Groups $\times$ Pre-post & 0.003 & 1 & 0.954 & 0.995 & \\
\hline \multirow[t]{3}{*}{ TAP- selective attention } & Groups & 0.080 & 1 & 0.776 & 0.995 & \\
\hline & Pre-post & 0.004 & 1 & 0.983 & 0.995 & \\
\hline & Groups $\times$ Pre-post & 0.001 & 1 & 0.995 & 0.995 & \\
\hline \multirow[t]{3}{*}{ TAP- vigilance } & Groups & 0.298 & 1 & 0.585 & 0.995 & \\
\hline & Pre-post & 0.667 & 1 & 0.414 & 0.995 & \\
\hline & Groups $\times$ Pre-post & 0.367 & 1 & 0.544 & 0.995 & \\
\hline \multirow[t]{3}{*}{ Token Test } & Groups & 0.202 & 1 & 0.652 & 0.995 & \\
\hline & Pre-post & 0.011 & 1 & 0.914 & 0.995 & \\
\hline & Groups $\times$ Pre-post & 0.298 & 1 & 0.584 & 0.995 & \\
\hline \multirow[t]{3}{*}{ Tower of London } & Groups & 0.008 & 1 & 0.925 & 0.995 & \\
\hline & Pre-post & 1.673 & 1 & 0.195 & 0.720 & \\
\hline & Groups $\times$ Pre-post & 0.099 & 1 & 0.752 & 0.995 & \\
\hline \multirow[t]{3}{*}{ Verbal and Semantic Fluency } & Groups & 5.911 & 1 & $0.020^{*}$ & $\mathbf{0 . 1 2 9}^{* *}$ & $\mathrm{~S} \& \mathrm{M}>\mathrm{B} \& \mathrm{~L}$ \\
\hline & Pre-post & 0.174 & 1 & 0.676 & 0.995 & \\
\hline & Groups $\times$ Pre-post & 0.014 & 1 & 0.903 & 0.995 & \\
\hline \multirow{3}{*}{ WCST } & Groups & 0.111 & 1 & 0.738 & 0.995 & \\
\hline & Pre-post & 0.254 & 1 & 0.614 & 0.995 & \\
\hline & Groups $\times$ Pre-post & 0.151 & 1 & 0.697 & 0.995 & \\
\hline
\end{tabular}

Main results: Outcomes of neuropsychological tests administered. GLMMs with score as dependent variable; groups, pre-post as fixed effect; ID subjects and levels as random effects. The rightmost column shows the order of means (from the largest to smallest) for the significant results. Note: $\mathrm{WCST}=$ Wisconsin Card Sorting Test; TAP $=$ Test of Attentional Performance; ${ }^{*}$ significant $(p$-value $<0.05)$; ** significant FDR (FDR < 0.15).

group therapy than before, demonstrating efficacy of treatment; in other words, patients, through the role play technique, experienced directly their difficulties; however, patients tended to consider their perfor- mance better than their relatives. An overestimation of abilities was more evidenced in S\&M Group. This may be due to caregiver's distress, although coping of the caregivers was not among the aims of the present 
Table 4

Power-study for significant analysis shown in Tables 2 and 3

\begin{tabular}{lcccccc}
\hline TEST & $\begin{array}{c}\text { Difference } \\
\text { of means } \\
\text { (absolute value) }\end{array}$ & $\begin{array}{c}\text { Standard } \\
\text { deviation } \\
\text { in B\&L }\end{array}$ & $\begin{array}{c}\text { Standard } \\
\text { deviation } \\
\text { in S\&M }\end{array}$ & $\begin{array}{c}\text { Ratio } \\
\text { in sample } \\
\text { size B\&L/S\&M }\end{array}$ & $\begin{array}{c}\text { Number } \\
\text { of cases } \\
\text { required in B\&L }\end{array}$ & $\begin{array}{c}\text { Number } \\
\text { of cases } \\
\text { required in S\&M }\end{array}$ \\
\hline Awareness questionnaires & & & & & & \\
PCRS & 3.98 & 1.381 & 1.825 & 1.25 & 4 & 4 \\
AQ & 3.525 & 1.96 & 1.57 & 1.25 & 5 & 4 \\
SADI & 1.998 & 0.468 & 1.025 & 1.25 & 4 & 4 \\
Neuropsychological data & 1.51 & 0.307 & 0.857 & 1.25 & 5 & 4 \\
BADA & 1.775 & 0.383 & 0.816 & 1.25 & 4 & 4 \\
Corsi Span & 2.75 & 1.26 & 1.3 & 1.25 & 5 & 4 \\
Digit Span Forward & 3.15 & 1.2 & 1.145 & 1.25 & 4 & 4 \\
Episodic memory & 3.95 & 1.99 & 1.78 & 1.25 & 5 & 4 \\
Raven Progressive Matrices & 90.01 & 42.69 & 36.35 & 1.25 & 4 & 4 \\
TAP alertness (with sound) & 7.25 & 3.05 & 3.09 & 1.25 & 4 & 4 \\
Verbal and Semantic Fluency & & & & & 4 \\
\hline
\end{tabular}

study and the reliability of the caregivers is universally recognized as a crucial challenge in all studies on self-awareness of persons with TBI. It is important to note that the family members may present with psychological defence mechanisms such as denial and the non-acceptance of the patient's dysfunction; also, rehabilitation hospital is a protected environment, thus the problems are more difficult to be observed by the relatives during inpatient rehabilitation. Furthermore, it is also interesting to note that lower ratings are found in particular for relatives of S\&M Group in which the activities are based on current difficulties.

According to Sherer and colleagues (Sherer, 2003b), patient clinician discrepancies appear to be a more effective measure than patient family discrepancy to assess SA, especially in the early phase. In the present study we chosed to compare relatives, instead of the clinicians' report, to the patientsself-report, since we enrolled only patients in the post-acute phase and, accordingly, their caregivers were the most reliable witnesses of the level of functioning in patients' everyday life, especially in our "open" rehabilitation hospital, where the presence of the relatives is allowed for the whole day.

Secondarily, in both AQ and PCRS questionnaires, more discrepancies scores in cognitive domain were found (the rightmost column of Table 2 shows the order of means, from the largest to the smallest). Even after treatment, patients rated themselves as higher functioning than did their relatives, particularly for affective and cognitive domains; instead motor-sensory domain showed best agreement also at baseline (Table 2).

However, the efficacy of both treatments was also evidenced by clinician ratings using SADI. It is worthnoting that the clinical evaluation by means of the SADI, has been conducted by a blind clinician, to avoid bias due to expectations of the group leader. Overall, the blind clinician observed an improvement in awareness in both groups. In particular, after both group therapies, patients showed an improvement in self-awareness at both intellectual and emergent levels.

Regarding neuropsychological changes, in support to the importance of a specific rehabilitation of self-awareness, a group-related improvement was observed on specific cognitive domains. These findings suggest that a specific group therapy can improve neuropsychological functioning together with individual cognitive rehabilitation, carried out in all patients enrolled in this study. In particular, attention and executive functions in S\&M group improved after treatment. Secondary, considering both groups in pre-post condition, other significant effects have occurred particularly in memory deficits (both short and long term memory) and attention functions. Lastly, we observed a general improvement before and after therapies also in language disorders, memory deficits and logical reasoning. In the S\&M group, in agreement with previous studies, that investigated the correlation between executive function and SA (Noè et al., 2005; Bivona et al., 2008, 2013; Ciurli et al., 2010), a significant improvement on Verbal and Semantic Fluency was observed. Fluency tasks as a tool to assess executive control ability is also well documented. Executive control is a set of functions that include monitoring, shifting and inhibition of dominant responses. The improvement that we found in these abilities means that improving the awareness by means of the group dynamics and feedback, may lead to a greater control over their performance or to a better control on self-monitoring capability. Indeed, social disability of individuals with low SA may be also due to the poor opportunities of social feedback 
(Bivona et al., 2015). Actually the activities in S\&M Group, regarding emotions and emotional experiences, improved self-awareness disorders, likely due to an effect on control of their impulses and responses.

In addition, a general improvement observed in both attention, memory and logical reasoning, means that awareness improvement may lead also to a better control of own performance and particularly to own cognitive deficits.

In the present study two important findings are evidenced. First, regardless of the group therapy, it is important to investigate and treat self-awareness, also to improve the outcome of the neuropsychological disorders as a whole. Second, the two group therapies proposed seem to be specific and could be alternatively be preferred, in the presence of impulsivity and emotional dyscontrol (S\&M) and for memory, logical reasoning and attention disorders (both B\&L and S\&M).

\subsection{Limitations of the study}

Even if SA data collected in this study are based on patients, relatives and clinicians, according to an overall perspective, the small sample size strongly imposes caution in generalization of the results. A control group would also have made the results more reliable to determine whether the results could be attributed to the specific group therapy programme, to individual cognitive therapy or to spontaneous recovery. Finally, long term follow-up of SA level for the included participants would have been of additional and valuable interest for these preliminary results.

\section{Conclusion}

To our knowledge, this is an innovative comparison between two different group therapy approaches, to treat disorders of self-awareness in persons with severe TBI. The dynamic interactions and feedback of the participants seem to have a beneficial effect non only on the self-awareness disorder but also on the neuropsychological deficits as a whole.

Further studies to confirm these preliminary and promising results are warranted.

\section{Acknowledgments}

We thank all participants who took part in this study. We wish to thank Claire Montagna for helping in English revision.

\section{Declaration of interest}

The authors report no conflict of interest. There was no funding source that assisted with the completion of this study.

\section{References}

Artiola, L., Fortuny, I., Briggs, M., Newcombe, F., Ratcliff, G., \& Thomas, C. (1980). Measuring the duration of post traumatic amnesia. Journal of Neurology Neurosurgery and Psychiatry, 43, 377-379.

Basso, A., Capitani, E., \& Laiacona, M. (1987). Raven's coloured progressive matrices: Normative values on 305 adult normal controls. Functional Neurology, 2(2), 189-194.

Bates, D., Maechler, M., Bolker, B., \& Walker, S. (2015). Fitting Linear Mixed-Effects Models Using lme4. Journal of Statistical Software, 67(1), 1-48.

Benjamini, Y., \& Yekutieli, D. (2001). The control of the false discovery rate in multiple testing under dependency. Annals of Statistics, 29, 1165-1188.

Benjamini, Y., \& Hochberg, Y. (1995). Controlling the false discovery rate: A practical and powerful approach to multiple testing. Journal of the Royal Statistical Society, 57, 289-300.

Ben-Yishay, Y., \& Lakin, P. (1989). Structured group treatment for brain injury survivors. In: Ellis, D. W., \& Christensen, A. L. (Ed.), Neuropsychological Treatment After Brain Injury. Kluwer Academic Publishers, Boston, pp. 271-295

Ben-Yishay, Y., Rattok, J., Lakin, P., Piasetsky, E. G., Ross, B., Silver, S., Zide, E., \& Ezrachi, I. (1985). Neuropsychological rehabilitation: Quest for a holistic approach. Seminars in Neurology, 5, 252-259.

Bianchi, I., Savardi, U., Burro, R., \& Martelli, M. F. (2014). Doing the opposite to what another person is doing. Acta Psychologica, 151, 117-133.

Bianchi, I., Burro, R., Torquati, S., \& Savardi, U. (2013). The middle of the road: Perceiving intermediates. Acta Psychologica, 144(1), 121-135.

Bivona, U., Formisano, R., De Laurentiis, S., Accetta, N., Di Cosimo, M. R., Massicci, R., Ciurli, P., Azicnuda, E., Silvestro, D., Sabatini, U., Falletta Caravasso, C., Carlesimo G. A., Caltagirone, C., \& Costa, A. (2015). Theory of mind impairment after severe traumatic brain injury and its relationship with caregivers' quality of life. Restorative Neurology and Neuroscience, 33(3), 335-345.

Bivona, U., Riccio, A., Ciurli, P., Carlesimo, G. A., Delle Donne, V., Pizzonia, E., Caltagirone, C., Formisano, R., \& Costa, A. (2014). Low self-awareness of individuals with severe traumatic brain injury can lead to reduced ability to take another person's perspective. The Journal of Head Trauma Rehabilitation, 29(2), 157-171.

Bivona, U., Ciurli, P., Barba, C., Onder, G., Azicnuda, E., Silvestro, D., Mangano, R., Rigon, J., \& Formisano, R. (2008). Executive function and metacognitive self-awareness after Severe Traumatic Brain Injury. Journal of the International Neuropsychological Society, 14, 862-868. 
Box, G. E. P., \& Cox, D. R. (1964). An analysis of transformations. Journal of the Royal Statistical Society B, 26, 211-252.

Branchini, E., Burro, R., Bianchi, I., \& Savardi, U. (2015). Contraries as an effective strategy in geometrical problem solving. Thinking and Reasoning, 21(4), 397-430.

Carlesimo, G. A., Caltagirone, C., Gainotti, G., Fadda, L., Gallassi, R., Lorusso, S., Marfia, G., Marra, C., Nocentini, U., \& Parnetti, L. (1996). The Mental Deterioration Battery: Normative data, diagnostic reliability and quantitative analyses of cognitive impairment. European Neurology, 36, 378-384.

Carberry, H., \& Burd, B. (1983). Social aspects of cognitive retraining in an outpatient group setting for head trauma patients. Cognitive Rehabilitation, 1(6), 5-7.

Cicerone, K. D. (1991). Psychotherapy after mild traumatic brain injury: Relation to the nature and severity of subjective complaints. Journal of Head Trauma Rehabilitation, 6, 30-43.

Ciurli, P., Bivona, U., Barba, C., Onder, G., Silvestro, D., Azicnuda, E., Rigon, J., \& Formisano, R. (2010). Metacognitive unawareness correlates with executive function impairment after severe traumatic brain injury. Journal of the International Neuropsychological Society, 16, 360-368.

Crosson, B., Barco, P. P., Velozo, C. A., Bolesta M. M., Cooper, P., Werts, D., \& Brobeck, T. (1989). Awareness and compensation in postacute head injury rehabilitation. Journal of Head Trauma Rehabilitation, 4, 46-54.

Dikmen, S. A., Temkin, N., Machamer, J., Hulubkov, A. L., Fraser, R. T., \& Winn, R. (1994). Employment following traumatic head injuries. Archives of Neurology, 51, 177-186.

Dikmen, S., McLean, A. Jr., Temkin, N. R., \& Wyler, A. R. (1986). Neuropsychologic outcome at one-month post-injury. Archives of Physical Medicine and Rehabilitation, 67(8), 507513.

Fisher, J. E, Mohanty, A., Herrington, J. D., Koven, N. S., Miller, G. A., \& Heller, W. (2004). Neuropsychological evidence for dimensional schizotypy: Implications for creativity and psychopathology. Journal of Research in Personality, 38, 24-31.

Flashman, L. A., \& McAllister, T. W. (2002). Lack of awareness and its impact in traumatic brain injury. Neurorehabilitation, 17, 285-296.

Fleming, J. M., Strong, J., \& Ashton, R. (1998). Cluster analysis of self-awareness levels in adults with traumatic brain injury and relationship to outcome. Journal of Head Trauma Rehabilitation, 13, 39-51.

Fleming, J. M., Strong, J., \& Ashton, R. (1996). Cluster analysis of self-awareness levels in adult with traumatic brain injury and relationship to outcome. Journal of Head Trauma Rehabilitation, 13, 39-59.

Freeland, J. (1996). Awareness of deficits: A complex interplay of neurological, personality, social and rehabilitation factors. Magazine, 4, 32-34.

Fryer, L. J., \& Haffey, W. J. (1987). Cognitive rehabilitation and community readaptation: Outcomes from two program models. Journal of Head Trauma Rehabilitation, 2(3), 51-63.

Godfrey, H. P., Partridge, F. M., Knight, R. G., \& Bishara, S. (1993). Course of insight disorder and emotional dysfunction following closed head injury: A controlled cross-sectional follow-up study. Journal of Clinical and Experimental Neuropsychology, 15, 503-515.
Hall, K. M., Cope, D. N., \& Rappaport, M. (1985). Glasgow outcome scale and Disability Rating Scale: Comparative usefulness in following recovery in traumatic head injury. Archives Physical Medicine and Rehabilitation, 66, 35-37.

Hagen, C., Malkmus, D., \& Durham, P. (1972). Levels of cognitive functioning. Rancho Los Amigos Hospital, Downey (CA).

Hochberg, Y. (1988). A sharper Bonferroni procedure for multiple tests of significance. Biometrika, 75, 800-803.

Holm, S. (1979). A simple sequentially rejective multiple test procedure. Scandinavian Journal of Statistics, 6, 65-70.

Hommel, G. (1988). A stagewise rejective multiple test procedure based on a modified Bonferroni test. Biometrika, 75, 383-386.

Jannett, B., \& Bond, M. (1975). Assessment of outcome after severe brain damage. Lancet, 1(7905), 480-484.

Katz, D. I., \& Alexander, M. P. (1994). Predicting outcome and course of recovery in patients admitted to rehabilitation. Archives of Neurology, 51, 661-670.

Krikorian, R., Bartok, J., \& Gay, N. (1994). Tower of London procedure: A standard method and developmental data. Journal of Clinical and Experimental Neuropsychology, 16(6), 840-850.

Levin, H. S., O’Donnell, V. M., \& Grossman, R. G. (1979). The Galveston Orientation and Amnesia Test: A practical scale to assess cognition after head injury. Journal of Nervous and Mental Diseases, 67, 675-684.

Lundqvist, A., Linnros, H., Orlenius, H., \& Samuelsson, K. (2010). Improved self-awareness and coping strategies for patients with acquired brain injury-a group therapy programme. Brain Injury, 24(6), 823-32.

Markova, I. S., \& Berrios, G. E. (2006). Approaches to the assessment of awareness: Conceptual issues. Neuropsychological Rehabilitation, 16(4), 439-455.

Mazzucchi, A., \& Avanzi, S. (1997). Disturbi post-traumatici del linguaggio. In: Mazzucchi, A., (Ed.), La riabilitazione neuropsicologica dei traumatizzati cranici. II ediz., Masson, Milano, pp. 75-100.

McDonald, J. H. (2014). Handbook of Biological Statistics (3rd ed.). Sparky House Publishing, Baltimore, Maryland.

Menon, D. K., Schwab, K., Wright, D. W., \& Maas, A. I. (2010). Position Statement: Definition of Traumatic Brain Injury. Archives of Physical Medicine and Rehabilitation, 91(11), 1637-1640.

Moore, A. D., \& Stambrook, M. (1995). Cognitive moderators of outcome following traumatic brain injury: A conceptual model and implications for rehabilitation. Brain Injury, 9, 109-130.

Noè, E., Ferri, J., Caballero, M. C., Villadre, R., Sanchez, A., \& Chirivella, J. (2005). Self-awareness after acquired brain injury. Predictors and rehabilitation. Journal of Neurology, 252, 168-175.

Novack, D. H., Dubé, C., \& Goldstein, M. G. (1992). Teaching medical interviewing. A basic course on interviewing and the physician-patient relationship. Archives of Internal Medicine, 152(9), 1814-1820.

Novelli, G., Papagno, C., Capitani, E., Laiacona, M., Vallar, G., \& Cappa, S. F. (1986). Three clinical tests to research and rate the lexicalperformance of normal subjects. Archivio di Psicologia Neurologia e Psichiatria, 47, 477-506. 
Orsini, A. (2003). La memoria diretta e la memoria inversa di cifre in soggetti dai 16 ai 64 anni. Bollettino di Psicologia Applicata, 239, 73-77.

Orsini, A., Grossi, D., Capitani, E., Laiacona, M., Papagno, C. \& Vallar, G. (1987). Verbal and spatial immediate memory span: Normative data from 1355 adults and 1112 children. The Italian Journal of Neurological Science, 8, 537-548.

Ownsworth, T., \& Clare, L. (2006). The association between awareness deficits and rehabilitation outcome following acquired brain injury. Clinical Psychology Review, 26, 783795 .

Prigatano, G. P., Borgaro, S., Baker, J., \& Wethe, J. (2005). Awareness and distress after traumatic brain injury: A relative's perspective. Journal of Head Trauma Rehabilitation, 20(4), 359-367.

Prigatano, G. P., Bruna, O., Mataro, M., Munoz, J. M., Fernandez, S., \& Junque, C. (1998). Initial disturbances of consciousness and resultant impaired awareness in Spanish patients with brain injury. Journal of Head Trauma Rehabilitation, 13, 2938 .

Prigatano, G. P., \& Schacter, D. L. (1991). Introduction. In: Prigatano, G. P. \& Schacter, D. L. (Ed.), Awareness of deficit after brain injury: Clinical and theoretical issues. Oxford University Press, New York, pp. 3-15.

Prigatano, G. P., \& Altman, I. M. (1990). Impaired awareness of behavioural limitations after traumatic brain injury. Archives of Psysical Medicine and Rehabilitation, 71, 1058-1064.

Prigatano, G. P., Fordyce, D. J., Zeiner, H. K., Roueche, J. R., Pepping, M., \& Wood, B. C. (1986). Neuropsychological rehabilitation after brain injury. Johns Hopkins University Press, Baltimore.

R Core Team (2015). R: A language and environment for statistical computing. Vienna, Austria: R Foundation for Statistical Computing. Retrieved on 25/01/2015 from https://www.Rproject.org/

Rappaport, M. (2005). The Disability Rating Scale and Coma/Near Coma scales in evaluating severe head injury. Neuropsychological Rehabilitation, 15(3/4), 442-453.

Rappaport, M. Herrero-Backe, C., Rappaport, M. L., \& Winterfield, K. (1989). Head injury outcome up to ten years later. Archives of Physical Medicine and Rehabilitation, 70, 885892.

Rappaport, M., Hall, K. M., Hopkins, K., Belleza, T., \& Cope, D. N. (1982). Disability rating scale for severe head trauma: Coma to community. Archives Physical Medicine and Rehabilitation, 63, 118-123.

Raven, J. C. (1954). Standard progressive matrices. Organizzazioni Speciali, Firenze.
Sbordone, R. J., Seyranian, G. D., \& Ruff, R. M. (1998). Are the subjective complaints of traumatically brain injured patients reliable? Brain injury, 12(6), 505-515.

Schmidt, J., Lannin, N., Fleming, J., \& Ownsworth, T. (2011). Feedback interventions for impaired self-awareness following brain injury: A systematic review. Journal of Rehabilitation Medicine, 43, 673-680.

Sherer, M., Hart, T., \& Nick, T. G. (2003a). Measurement of impaired self-awareness after traumatic brain injury: A comparison of the patient competency rating scale and the awareness questionnaire. Brain Injury, 17, 25-37.

Sherer, M., Hart, T., Nick, T. G., Whyte, J., Thompson, R. N., \& Yablon, S. A. (2003b). Early impaired self-awareness after traumatic brain injury. Archives of Physical Medicine Rehabilitation, 84(2), 168-176.

Sherer, M., Bergloff, P., Levin, E., High, W. M., Oden, K. E., \& Nick, T. G. (1998a). Impaired awareness and employment outcome after traumatic brain injury. Journal of Head Trauma Rehabilitation, 13, 52-61.

Sherer, M., Bergloff, P., Boake, C., High, W. Jr., \& Levin, E. (1998b). The Awareness Questionnaire: Factor structure and internal consistency. Brain Injury, 12, 63-68.

Sherer, M., Oden, K., Bergloff, P., Levin, E., \& High, W. M. Jr. (1998c). Assessment and treatment of impaired awareness after brain injury: Implications for community re-integration. NeuroRehabilitation, 10(1), 25-37.

Simes, R. J. (1986). An improved Bonferroni procedure for multiple tests of significance. Biometrika, 73, 751-754.

Simmond, M., \& Fleming, J. (2003). Reliability of the selfawareness of deficits interview for adults with traumatic brain injury. Brain Injury, 17(4), 325-337.

Sohlberg, M. M., Mateer, C. A., Penkman, L., Giang, A., \& Todis, B. (1998). Awareness intervention: Who needs it? The Journal of Head Trauma Rehabilitation, 13(5), 62-78.

Sohlberg, M. M., \& Mateer, C. A. (1989). Introduction to cognitive rehabilitation: Theory and practise. Guilford Press, New York.

Spencer, E. A. (1993). Functional restoration. In: Hopkins, H. L., \& Smith, H. (Ed.), Willard and spackman's occupational therapy. JB Lippincott Co., Philadelphia.

Stuss, D. T., \& Benson, D. F. (1986). The frontal lobes. Raven Press, New York.

Toglia, J., \& Kirk, U. (2000). Understanding awareness deficits following brain injury. Neurorehabilitation, 15, 57-70.

Wood, R. L. (2008). Long-term outcome of serious traumatic brain injury. European Journal of Anaesthesiology, 42, 115-122.

Zimmerman, P., \& Fimm, B. (1992). Test Batterie zur Aufmerksamkeitsprufung (TAP). Psytest, Wurselen Germany. 